\title{
Difficulties in the diagnosis of meningitis - a challenging case of a child with head injury
}

\author{
Maria Gregorczyk $\mathbf{k}^{1, A-D, F \oplus}$, Jan Stachurski ${ }^{2, A-B, E-F \oplus}$ \\ 1 Student Research Association of Paediatric Emergency Medicine, Medical University, Warsaw, Poland \\ 2 Department of Emergency Medical Services, Faculty of Health Sciences, Medical University, Warsaw, Poland \\ $A$ - Research concept and design, B - Collection and/or assembly of data, C - Data analysis and interpretation, \\ $D$ - Writing the article, E - Critical revision of the article, F- Final approval of the article
}

\begin{abstract}
Gregorczyk M, Stachurski J. Difficulties in the diagnosis of meningitis - a challenging case of a child with head injury. J Pre-Clin Clin Res. 2022; 16(1): 6-8. doi: 10.26444/jpccr/145567
\end{abstract}

\begin{abstract}
I Abstract
Meningitis is a potentially life-threatening condition. The clinical manifestation can vary depending on the age of the child. This report presents the case of a 7-year-old male patient who was admitted to ED due to loss of consciousness after a head injury. Upon admission, the patient had seizures. Head CT scan did not show any signs of intracerebral bleeding or cerebral oedema. During hospitalization in the ICU, the patient began to be febrile and inflammatory markers started to rise. Treatment with antibiotics and antiviral agents was administered. Later, meningeal signs were observed. Additional imaging tests revealed ambiguous findings. The patient's symptoms resolved gradually, and he was discharged after 19 days of hospitalization. The final diagnosis was meningitis. This case highlights that the diagnosis of meningitis requires careful investigation and precise examination. This diagnosis should therefore be considered in all patients who present with symptoms concerning for meningitis.
\end{abstract}

\section{Key words}

meningitis, seizures, craniocerebral trauma, child, diagnosis, hospital emergency service

\section{INTRODUCTION}

Meningitis is a potentially life-threatening condition characterised by inflammation of the brain meninges. In 2019 in Poland, the incidence rate for bacterial meningitis was 2.41 per 100,000 per year, while for viral meningitis it was 3.43 per 100, 00 per year. The most common etiological factors for bacterial meningitis were N. meningitidis, S. pneumoniae, and H. influenzae (31\%) and neuroborreliosis (31.92\%). Cases of viral meningitis were most often caused by other specified and unspecified etiological factors (61.2\%), enteroviruses and herpesviruses [1]. The diagnosis of meningitis can be challenging because the clinical manifestation varies by age and the presented symptoms are non-specific. In general, the most common symptoms of meningitis are fever, headache, photophobia, nausea, and vomiting [2]. Typical meningeal signs - nuchal rigidity, Kernig's sign, and Brudzinski's sign - are observed only in approximately half of the patients [3]. Differential diagnosis should include diseases associated with increased intracranial pressure and meningeal irritation, such as trauma, intracranial haemorrhage, or neoplastic disorders [4].

\section{OBJECTIVE}

The aim of this case report was to present the diagnostic process of a patient with meningitis, and to highlight the challenges that occur during the process.

Address for correspondence: Jan Stachurski, Department of Emergency Medical Services, Faculty of Health Sciences, Medical University of Warsaw, Litewska 14/16, 00-575 Warsaw, Poland

E-mail: jan.stachurski@wum.edu.pl

Received: 10.12.2021; accepted: 05.01.2022; first published: 21.01.2022

\section{MATERIALS AND METHOD}

The research material for this case report was collected on the basis of the medical records of th Paediatric Teaching Clinical Hospital University Clinical Centre of the Medical University of Warsaw, obtaining the appropriate consent from the Director of the Hospital, and following the provisions of the Polish Act on Patient Rights and Patient's Rights Ombudsman. In accordance with the Helsinki Declaration, the case report was fully anonymised, and none of the data presented in it make it possible to identify the patient. Photos were not presented to increase the degree of anonymity. The presentation of this case does not require the consent of the Bioethics Committee in accordance with the requirements of Polish law.

\section{CASE STUDY}

A 7-year-old male patient was admitted to the Emergency Department of Paediatric Teaching Clinical Hospital University Clinical Centre of the Medical University in Warsaw, with loss of consciousness after a head injury. According to a witness, the patient fell while running. Immediately after the accident, there was no loss of consciousness. About 1.5 hours after the event, the child started to become confused and had memory impairment; trismus and jaw tremor were also observed. The patient had an episode of vomiting and lost consciousness.

The child was otherwise healthy, with no previous head injuries, loss of consciousness, or significant medical history. Patient had been diagnosed with autism spectrum disorder and was under the care of psychologist. He was vaccinated according to the Polish immunization schedule against tuberculosis, hepatitis B, diphtheria, tetanus and pertussis, 
polio, Hib, and with the MMR vaccine. He had also been additionally vaccinated with pneumococcal vaccine. The patient reported a 2-day history of rhinitis with no other symptoms of infection.

On admission, the patient was unconscious and had a tonic seizure with upward deviation of the eyes, and spasticity of upper and lower limbs. He had equal and dilated pupils, slowly reacting to light. His Glasgow Coma Scale (GCS) was 4. The patient was treated with diazepam, which terminated the seizures and his GCS improved to 6 .

The preliminary diagnosis was brain trauma; therefore, in the Emergency Department imaging studies were performed to evaluate the head injury. A head and cervical spine computer tomography (CT) scan showed no abnormality, no signs of intracranial bleeding or increased intracranial pressure. However, his condition remained critical (GCS 7) and while no diagnosis could be made, the decision was taken to admit the patient to the Intensive Care Unit. Patient was intubated and on the second day of hospitalization he began to be febrile, with a temperature of $37.7-37.9^{\circ} \mathrm{C}$, with single increase to $39.0^{\circ} \mathrm{C}$. Inflammatory markers, C-reactive protein (CRP) and procalcitonin (PCT) began to rise (Tab. 1). Ceftriaxone, vancomycin and acyclovir were administered.

Further investigation included lumbar puncture and the results of cerebrospinal fluid (CSF) analysis were as follows: cell count of 10 per $\mu \mathrm{l}$, lactate $1,2 \mathrm{mmol} / \mathrm{L}$, decreased level of proteins $(10 \mathrm{mg} / \mathrm{dl})$ and normal level of glucose. On the third day of hospitalization, patient regained consciousness, he was extubated and 2 days later he was transferred to the Paediatric Unit.

The treatment with antibiotics and acyclovir was continued. Physical examination revealed meningeal signs, including a nuchal rigidity, Kernig's and Brudziński's signs. Additional imaging tests included head magnetic resonance imaging (MRI) and electroencephalography (EEG). Analysis of MRI did not show any significant changes. EEG showed an increased number of slow waves.

After 10 days of antibiotic therapy, a control lumbar puncture was performed. The results were normal. Testing for enteroviruses, adenoviruses, Herpes Simplex Virus 1 (HSV1), HSV-2, Varicella-Zoster Virus (VZV) and tick-borne encephalitis virus were negative, as well as bacterial culture.

The clinical condition of a patient improved and he was finally discharged after 19 days of hospitalization. The final diagnosis was meningitis, and the patient was advised further neurological investigation.

Table 1. Laboratory investigations of the patient during hospitalization

\begin{tabular}{lcc}
\hline & CRP $[\mathrm{mg} / \mathrm{dl}]$ & PCT $[\mathrm{ng} / \mathrm{ml}]$ \\
& Ref. range: $0.0-1.0 \mathrm{mg} / \mathrm{dl}$ & Ref. range: $<0,05 \mathrm{~nm} / \mathrm{ml}$ \\
\hline DAY 0 & $0.7-0.8$ & $<0.05$ \\
\hline DAY 2 & 3.9 & 1.1 \\
\hline DAY 3 & 14.3 & 15.88 \\
\hline DAY 4 & 12.8 & 10.88 \\
\hline
\end{tabular}

\section{DISCUSSION}

The presented case study highlights the many challenges that can occur in the diagnosis of meningitis in children. The neurological evaluation of a child, especially in an emergency condition, is often very difficult and requires specific differential procedures [5]. The initial management and treatment can be complicated, especially in a case of patients with additional disorders [6].

The presented patient was admitted to hospital with the preliminary diagnosis of seizures and head injury. Later, it was found out that these are the symptoms of meningitis and not the head injury itself. The meningeal signs were observed in clinical examination only after few days of hospitalization. On admission, the inflammatory markers were not elevated, and patient was not feverish, which is characteristic for meningitis. Additionally, the analysis of CSF was ambiguous. The combination of all these factors resulted in a difficult diagnostic process and long hospitalization.

Meningitis is a serious infectious disease which untreated can cause neurological complications and neurological sequelae. Therefore, it requires prompt diagnosis and adequate treatment. In the case of bacterial meningitis, the administration of antibiotics is recommended as soon as possible, as treatment delays result in increased mortality and unfavourable outcomes at discharge [7]. What is more, hospitalization in the ICU can cause many complications, both neurological and concerning other systems [8].

Diagnosis can be challenging because clinical presentation of meningitis varies with age and symptoms are often nonspecific [9]. According to a study among Polish children, the most common symptoms of meningitis were headache, fever, vomiting and neck stiffness, and only $4 \%$ presented with seizures and $18 \%$ had altered level of consciousness [10]. A Swedish study investigated the differences in clinical presentation of acute bacterial meningitis in children according to age. It was found that younger children (aged 1-4 years) were more likely to present critical clinical condition. They presented with altered mental status, seizures, fatigue, and anorexia, whereas older children (aged 5-17 years) presented with more specific symptoms, such as headache, photophobia, vertigo, and increased pain sensitivity, as well as fever, nausea, and vomiting [11]. Table 2 presents symptoms and physical findings observed in the presented patient with its occurrence (in percentages) in different age groups, based on the cited study.

Table 2. Selected symptoms and physical findings in younger and older children

\begin{tabular}{lcc}
\hline Symptoms and physical examination & 1 month -4 years old & 5-17 years \\
\hline Altered mental status (\%) & 71 & 46 \\
\hline Seizures (\%) & 15 & 4 \\
\hline Fever (\%) & 31 & 21 \\
\hline GCS 14-15 (\%) & 31 & 54 \\
\hline GCS 11-13 (\%) & 37 & 29 \\
\hline GCS 9-10 (\%) & 27 & 14 \\
\hline GCS 3-8 (\%) & 5 & 4 \\
\hline Neck stiffness (\%) & 42 & 68 \\
\hline
\end{tabular}

Source: Johansson Kostenniemi U, Norman D, Borgstrom M, et al., 'The clinical presentation of acute bacterial meningitis varies with age, gender and duration of illness'. Acta Paediatr. 2015; 104(11): 1117-1124. https://doi.org/10.1111/apa.13149

Meningeal signs, often assessed during clinical examination, occur in only half of the patients. Different methods of examination meningeal signs differ in sensitivity and specificity, therefore a combination of several types 
should be used during clinical examination. The nuchal rigidity and jolt accentuation are suggested to have higher sensitivity, while Kernig's sign and Brudzinski's signs have higher specificity [3].

Another challenge in the diagnosis of meningitis is to quickly differentiate between viral and bacterial etiology and consequently introduce adequate treatment. Clinical presentation is similar for viral and bacterial meningitis, but the clinical condition of a patient with bacterial meningitis is generally more severe. Etiology can be identified after evaluation of CSF. Bacterial etiology can be diagnosed based on positive CSF culture. Other typical CSF results in patients with bacterial meningitis include: polymorphonuclear pleocytosis (white blood cells $>1,000$ Cells $/ \mu \mathrm{L}$ and $80-90 \%$ polymorphonuclear cells), decreased level of glucose $(<40 \mathrm{mg} /$ $\mathrm{dL}$ ) and elevated CSF protein levels (>150 mg/dL) [12]. Aseptic meningitis is associated with cell count of $10-1000$ per $\mu \mathrm{L}$, normal or slightly decreased glucose level, and normal or mildly elevated protein levels [13]. However, for some patients, especially children, the results of CSF analysis are unspecific.

Another marker that can be used in differential diagnosis is the serum procalcitonin level (PCT), which is much higher in bacterial meningitis. It is suggested that the PCT level is preferable for distinguishing between bacterial and aseptic meningitis in children, than the CRP level [14]. According to the literature, CSF lactate levels, polymorphonuclear neutrophils percentage, glucose levels and serum PCT concentration should always be analysed in the Emergency Departments, as they can be used to predict bacterial meningitis. The sensitivity and specificity of CSF lactate levels and serum PCT concentration are over 99\%. CSF lactate $>33 \mathrm{mg} / \mathrm{dL}$ and serum PCT concentration $>0,25 \mathrm{ng} /$ $\mathrm{dL}$ suggest bacterial meningitis [15].

\section{CONCLUSIONS}

Meningitis is a serious medical condition that requires prompt diagnosis and introduction of adequate treatment. It is a diagnostic challenge as the symptoms are often non-specific. Apart from the meningeal signs, additional laboratory tests, such as serum PCT concentration, CSF lactate levels, polymorphonuclear neutrophils percentage and glucose levels, can be helpful in making a definitive diagnosis.
Even in the case of patients with a head injury, another diagnosis, sometimes surprising, should be considered, which could be causing the patient's symptoms.

\section{REFERENCES}

1. Ochocka P, Zbrzeźniak J, Paradowska-Stankiewicz I. Meningitis and encephalitis in Poland in 2019. Przegl Epidemiol. 2021; 75(2): 215-228. https://doi.org/10.32394/pe.75.20

2. Okarska-Napierała M, Kuchar E. Zapalenie opon mózgowordzeniowych u dzieci - postępowanie praktyczne. Standardy Medyczne Pediatria. 2017; 14: 241-250.

3. Akaishi T, Kobayashi J, Abe M, et al. Sensitivity and specificity of meningeal signs in patients with meningitis. J Gen Fam Med. 2019; 20(5): 193-198. https://doi.org/10.1002/jgf2.268

4. Mount HR, Boyle SD. Aseptic and Bacterial Meningitis: Evaluation, Treatment, and Prevention. Am Fam Physician. 2017; 96(5): 314-322.

5. Ciechanowska M, Stachurski J. Differentiating stroke, transient ischemic attack, or hemiplegic migraine in a teenager: a case report. Med Sci Pulse. 2021; 15(3): 44-48. https://doi.org/10.5604/01.3001.0015.0631

6. Starobrat G, Taczała J, Fatyga M, et al. Posttraumatic Epidural Haematoma in a child with severe haemophilia A - case study. J PreClin Clin Res. 2019; 13(2): 76-78. https://doi.org/10.26444/jpccr/106100

7. Bodilsen J, Dalager-Pedersen M, Schønheyder HC, et al. Time to antibiotic therapy and outcome in bacterial meningitis: a Danish population-based cohort study. BMC Infect Dis. 2016; 392(16). https:// doi.org/10.1186/s12879-016-1711-z

8. Gałuszka DM, Poznańska A, Kunecki M, et al. Meningitis - case report. Emerg Med Serv. 2019; 6(3): 225-232. https://doi.org/10.36740/ EmeMS201903106

9. Shukla B, Aguilera EA, Salazar L, et al. Aseptic meningitis in adults and children: Diagnostic and management challenges. J Clin Viro. 2017; 94: 110-114. https://doi.org/ 10.1016/j.jcv.2017.07.016

10. Toczylowski K, Bojkiewicz E, Barszcz M, et al. Etiology, Clinical Presentation and Incidence of Infectious Meningitis and Encephalitis in Polish Children. J Clin Med. 2020; 9(8). https://doi.org/10.3390/ jcm9082324

11. Johansson Kostenniemi U, Norman D, Borgstrom M, et al. The clinical presentation of acute bacterial meningitis varies with age, sex and duration of illness. Acta Paediatr. 2015; 104(11): 1117-1124. https://doi. org/10.1111/apa.13149

12. Alamarat Z, Hasbun R. Management of Acute Bacterial Meningitis in Children. Infect Drug Resist. 2020; 13: 4077-4089. https://doi. org/10.2147/IDR.S240162

13. Kaur H, Betances, EM, Perera TB. Aseptic Meningitis. Treasure Island (FL): StatPearls Publishing, 2021.

14. El Shorbagy HH, Barseem NF, Abdelghani WE, et al. The value of serum procalcitonin in acute meningitis in children. J Clin Neurosci. 2018; 56: 28-33. https://doi.org/10.1016/j.jocn.2018.08.012

15. Julián-Jiménez A, Morales-Casado M. Utilidad de las determinaciones analíticas en sangre y líquido cefalorraquídeo para predecir meningitis bacterianas en el servicio de urgencias. Neurología. 2019; 34(2): 105-113. https://doi.org/10.1016/j.nrl.2016.05.009 